\title{
A propósito de las "sombras" que pueblan la poesía de Miguel Fernández: "El muchacho de chaleco rojo"
}

MANUEL CACERES SANCHEZ

Universidad de Granada

Mi contribución, mi lectura de un aspecto concreto de la obra poética de Miguel Fernández, parte de mi interés por el discurso literario como elemento integrado en ese conjunto de discursos que constituye, a través de una completa red de relaciones dinámicas, lo que llamamos "cultura". Desde ese punto de vista culturológico (en el sentido lotmaniano), la literatura se puede analizar como texto que mantiene las relaciones dialógicas: como texto compuesto por elementos que entran en correlación con otros elementos del mismo texto (es la función sínoma de la que habla Iuri Tynianov); como texto literario que forma parte del conjunto de textos literarios escritos en una lengua y de los textos literarios escritos en otras lenguas; como texto cuyo significado se construye también en su relación con otros sistemas de significado más amplios, con otros códigos, con otras normas de una cultura determinada espacial y temporalmente (1).

En esta ocasión me quiero referir a las relaciones del texto poético de Miguel Fernández con otros textos artísticos, incluido también el literario. Un tejido en el que el discurso poético propio se articula con textos de naturaleza diferente, aumentando así los planos o los niveles de lectura. 
Los estudiosos de su obra no han pasado por alto este rasgo, aunque no parecen estar muy de acuerdo acerca de la función que desempeña en su poesía. $Y$ es posible que no pueda ser de otro modo cuando pensamos en las dificultades que la obra de Miguel Fernández suele tener para un lector, si no especializado, sí al menos familiarizado con la poesía.

Las referencias de diverso tipo al mundo de la pintura, de la música o de la literatura se encuentran esparcidas por la mayoría de sus libros. Pero quizás sea en "Habitación poblada de sombras" (el poema de Sagrada materia, de 1967) donde se concentren el mayor número de nombres propios: Francis Jammes, Paul Cézanne y "el otro Pablo de la plaza de la Merced, Pablo Picasso, son las "amadas sombras" que acuden "a escuchar a los viejos camaradas/ que han puesto solaz en la frente de esta tribu adorada": estos "viejos camaradas" son Palestrina, Albinioni, Bach, Corelli, Vivaldi y Schönberg.

Ya apuntó con acierto Sultana Wahnón, en su libro El irracionalismo en la poesía de Miguel Fernández, que la aparición del nombre propio “cumple una función evocadora no de épocas, sino de significados emotivos o connotativos" (2). En este caso, el "recuento de [sus] amadas sombras" permite reflexionar a Miguel Fernández sobre la creación literaria misma. A quienes piensan que su poesía (y la poesía en general) no es más que una repetición de palabras "surgidas nuevamente como de otra cosecha/ que sólo es nuevo el grito, según sangre la herida; a quienes eso creen, el poeta les responde:
"Oh mis amigos demenciales, alzan su vino lleno de palabras como si fuera posible poner puertas al campo de lo que siempre fuimos: hombres en transmisión dorada a otras laderas".

Otros pintores como Van der Weyden (y la alusión a su Retablo de los Siete Sacramentos), compositores de música clásica como Guido D'Arezzo, Ravel, Verdi o Bedrich Smetana (pero también intérpretes de blues y jazz 
como el saxofonista y clarinetista Sidney Bechet), y escritores (desde Fray Luis a Lautréamont y Hölderlin) son también citados en sus poemas. Será, pues, esta especie de hermanamiento intelectual de Miguel Fernández con todos ellos el que nos pueda ayudar a entender la presencia de sus nombres en los versos del poeta.

No puedo en esta ocasión detenerme, por ejemplo, en un rasgo muy extendido en su obra poética, la sonoridad (en un sentido amplio), que abarca tanto el nivel puramente fónico, como las numerosas alusiones a seres y objetos que evocan sonidos (y hasta el silencio, que también habla, es motivo de algún poema). No se le escapó en su día a Francisco Rincón estudiar las técnicas que contribuyen a la sonoridad de la poesía de Miguel Fernández, entre las que destaca el contrapunto musical (3). Aunque no comparto del todo su interpretación de los nombres de los compositores, pues se basa en la idea de que éstos evocan en el poema determinadas épocas, considero de gran interés analizar con mayor detenimiento las funciones que desempeñan en su poesía las citas musicales, los nombres de músicos e instrumentos.

Me voy a centrar a continuación en el análisis de un poema. Este poema, además de ser uno de los que más me han gustado desde que lo leí hace diez años ( $\sin$ saber entonces nada sobre Miguel Fernández), puede servir como un buen ejemplo de la función evocadora que desempeñan los nombres (Aunque he de aclarar que, en cada poema, esa función evocadora remite a significados diferentes, $y$, en este sentido, cualquiera de esos casos servirían también como buenos ejemplos). El poema elegido es "El muchacho de chaleco rojo" (de Credo de libertad, de 1958).

Desde el título (y remarcado por la dedicatoria: "Homenaje a Paul Cézanne"), se nos está remitiendo al más conocido de la serie de tres retratos que, con el mismo título, fueron pintados por Cézanne entre 1890 y 1895. Se trata del lienzo, propiedad de la Colección Bührle (de Zúrich), que representa a un muchacho sentado, con el brazo izquierdo acodado en una mesa (donde se encuentra un papel en blanco) y la mano sosteniendo su cabeza, el brazo derecho semiextendido sobre las piernas (hasta las rodillas, que marcan el límite inferior de la tela), y mirando hacia el suelo, pensativo (4). 
Los especialistas de la obra de Cézanne coinciden en señalar que, en este período en que pinta El muchacho de chaleco rojo, la esquematización geométrica y el color, como elemento que marca la atmósfera del cuadro, se convierten en la base de su pintura. Y este retrato es una magnífica muestra de ello. En una carta al también pintor Émile Bernard escribe Cézanne las siguientes palabras, que luego se hicieron famosas:

"Tratar la naturaleza por medio del cilindro, de la esfera, del cono, todo ello puesto en perspectiva, de modo que cada lado de un objeto o de un plano se dirija hacia un punto central ${ }^{n}$.

Este punto central en $\mathrm{El}$ muchacho de chaleco rojo está situado en los límites mismos de la tela, incluso más allá si observamos la dirección de la mirada del personaje (que es una mirada perdida). Desde el centro del lienzo, ocupado por el torso, al igual que desde la parte superior (la cabeza) y desde el extreño inferior (el brazo derecho, que reposa suavemente en la pierna) se trazan líneas que se dirijen a un punto central que, utilizando el término cinmatográfico, se encuentra fuera de campo.

En el poema de Miguel Fernández encontramos marcas que evidencian la relación con el retrato. No es sólo el título y la dedicatoria. La deixis al principio del primer verso nos está situando ya frente al cuadro, nos traslada "al reino de lo ausente recordable [...] para que vea[mos] y oiga[mos] lo que allí hay que ver y oír" (son palabras de Karl Bühler, que define así lo que él llama una deixis en fantasma) (5):

"A ese muchacho de chaleco rojo, se le ha vaciado el corazón".

Y, en efecto, desde este lado, alguien — la voz del texto poético- nos habla de ese muchacho del chaleco rojo, interpreta sus sensaciones y pensamientos, nos hace ver y oír - parafraseando las palabras de Bühler- lo que sentiría y diría el personaje si pudiera hacerlo: 
"Si le apretáis los dedos, vais a sentir un guante en vuestra palma;

si le preguntáis por su hermana en Aix, os dirá que se ahogó en sus trenzas una mtarde que la lluvia era roja, como su chaleco.

Qué triste es tener un pecho vaciado, y unos dedos blandos que le cuelguen de niño por el camino nativo sin sentir que la carne huele a pradera húmeda. y decir:

'Mi hermana está muerta en un parque de Aix.

Mi hermana era tan dulce como Francis Jammes"?.

También desde el punto de vista estructural el poema guarda cierto vínculo con el modo de organización del texto pictórico. Así, mientras en las dos primeras estrofas, que acabo de leer, aparecen mencionados los dedos, el pecho y el corazón (es decir, la parte central y la inferior del retrato), en la última estrofa es la mirada del muchacho (en la perspectiva que sugiere el lienzo) la que el poeta resalta, dirigiéndose directamente a él. La analogía entre esta distribución y la del cuadro parece, pues, bastante clara:

"Te diré, que si miras a tu suelo, no verás más que un poco de incienso en la yerba y el viejo libro del mundo con muertas mariposas señalando la hoja de tu historia.

Mas si arañas la tierra, verás que allí debajo está tu hermana viva, tu nombre, tu familia, y ese chaleco húmedo por tu sangre, muchacho". 
Pero el poema, claro está, no es el cuadro. Éste le ha servido a Miguel Fernández como referente, como una realidad no lingúística que evoca el poema. Enrique Molina Campos y Sultana Wahnón han señalado el carácter simbólico o irracionalista de la poesía de Miguel Fernández, que presenta dos niveles (real e ideal) relacionados mediante el símbolo, que es "clave de representación de esta poesía", según dice Enrique Molina (6).

En el poema que comentamos, el plano o nivel real —esto es, según Sultana Wahnón, el significaco lógico que el poema nos ofrece (7)- está relacionado directamente con el referente (con la pintura de Cézanne): el poema puede leerse como una interpretación de los sentimientos del personaje del lienzo, una explicación lógica de la causa de su ensimismamiento y de su tristeza. Al muchacho "se le ha vaciado el corazón" y sus dedos son como "un guante", "blandos", insensibles, casi sin vida. La causa de su estado es, para la voz narradora en el poema, la muerte de su hermana en Aix".

En este punto, los planos real e ideal se mezclan. Se cita el nombre de la ciudad donde nació y pasó gran parte de su vida el pintor francés, se dice que la "hermana" del muchacho murió — como le ocurrió realmente a Cézanne- en Aix-en Provence una tarde lluviosa. ¿Quién es esta "hermana" muerta que, sin embargo, puede ser viva si "araña" la tierra? La respuesta habría que buscarla en el plano ideal, en "una realidad de segundo grado", como lo define Enrique Campos (8), y en los símbolos que relacionana amblos planos.

Para Sultana Wahnón, la "hermana" muerta expresaría la nostalgia de lo perdido, una nostalgia producida por la tristeza; y la "dulzura" que se atribuye a la "hermana" simbolizaría la presencia de Dios (en este caso, su ausencia, pues ha muerto) (9). Además, nos advierte que, en un poema escrito antes de publicar Credo de libertad, Miguel Fernández había utilizado ya un simbolizador semejante: el "hermano" que ha muerto, es, según Sultana Wahnón, "la fe en la posibilidad de trascender"(10). Concluye mi compañera, de forma sugerente, que la última estrofa del poema se puede leer del siguiente modo: a causa de esa añoranza, por no creer ya en la posibilidad de "trascender", "el hombre no se da cuenta — son pala- 
bras de Sultana Wahnón- de que esa 'hermana' sigue viva y de que sólo hace falta 'arañar' la 'tierra' [es decir, "buscar'] para encontrarla" (11).

En "Habitación poblada de sombras", en el poema al que nos hemos referido antes, se cita el nombre de Cézanne, pero también el de Francis Jammes, que en "El muchacho de chaleco rojo", es presentado como "dulce", es decir, simbolizaría la presencia de Dios (me pregunto si Dios no puede ser también el Creador, en general: Dios-Creador pero también el Artista-Creador como Dios). Aparece, además, en aquel poema la imagen de "arañar" la tierra, bajo la que encontraremos otro universo (me pregunto también si esta búsqueda es la de otra realidad, la realidad de la ficción artística). Se lee en ese poema de Sagrada materia lo siguiente:
"Hundo entonces mis manos en la raíz del hombre
y la mina habitada del carbón, alza el fruto
más negro del abismo
para sentir la soga
que entre cada garganta anudan los diablos".

Pero es que, además, el final de los dos poemas apunta en una dirección semejante. Si en "Habitación poblada de sombras" se elude a la "sagrada polifonía / del hombre distante" y a que no es posible cercar "lo que siempre fuimos: / hombres en transmisión dorada a otras laderas", en "El muchacho de chaleco rojo" se dice que, más allá de lo aparente ("un poco de incienso en la yerba / y el viejo libro del mundo / con muertas mariposas señalando la hoja de tu historia") se encuentra otra realidad: "tu hermana viva, / tu nombre, tu familia, / y ese chaleco húmedo por tu sangre, muchacho". Se trata, por tanto, de dos invitaciones a la búsqueda de "otras laderas", más allá de nuestro "suelo", a la búsqueda de un punto central que, como en la obra de Cézanne, también se halla fuera de campo. Y, por lo que sabemos de su poesía y de los estudios a ella dedicada, la obra de Miguel Fernández puede ser considerada, en su conjunto, desde esa perspectiva de incesante indagación. 
Se ha dicho que Cézanne que fue el primero en asignar a la pintura una función nueva: la de construir una realidad propia, regida por sus propias leyes formales, independientemente del dato natural o emotivo. Del poema que evoca el retrato del muchacho podríamos decir algo parecido: los versos de Miguel Fernández construyen una realidad propia, de acuerdo con sus propias leyes formales, independientemente de sus relaciones con el cuadro. Pero el análisis de esas relaciones nos abre también la posibilidad de buscar más allá de nuestro suelo.

Hace tres años, escribí un trabajo dedicado al relato literario y a su recreación en el cine y en la televisión (12). Comenzaba ese título con unas palabras de Gérard Genette; las mismas con las que hoy quiero finalizar mi intervención:

"Si se aman de verdad los textos - dice Genette-, se debe desear, de cuando en cuando, amar (al menos) dos a la vez".

Espero que, al menos, alguna de mis palabras sirva a alguien para amar, también estos dos textos: el de Cézanne y el de Miguel Fernández. 
1. Sobre esta perspectiva de estudio he realizado una edición que contiene trabajos recientes de Boris A. Uspenski y de Iuri M. Lotman, entre otros, asi como un estudio introductorio y una amplia selección bibliográfica:

Iuri M. Lotman y la Escuela Semiótica de Tartu-Moscú, treinta años después, en Discurso. Revista Internacional de Semiótica y Teoría Literaria, número 8, 1993.

2. Sultana Wahnón, El irracionalismo en la poesía de Miguel Fernández, Granada, Antonio Uhago Editor, 1983, p. 127.

3. Es cierto que Francisco Rincón advierte que esa interpretación puede que "no pase de ser una coincidencia". Para Rincón, se aprecia en la poesía de Miguel Fernández (hasta Eros y Anteros, que es el último libro que estudia en su trabajo de 1978) un "leve desajuste [...] entre el libro concreto del poeta y la música — su otra vocacióna través de los autores e instrumentos que menciona": los nombres barrocos en Sagrada materia (que, para la mayoría de la crítica, es un libro sobre los recuerdos de la guerra civil de 1936; aunque tanto Enrique Molina Campos como Sultana Wahrón creen que no es asi); el nombre de Guido Arezzo (tratadista musical y considerado como el fundador del sistema actual de notación musical) y de los instrumentos primitivos (como el banjo, la vihuela o el rabel) en libros que representan, según F. Rincón, un "agudo harroquismo de palabra". Concluye estas líneas dedicadas al "contrapunto musical" afirmando que la presencia de estos nombres en la obra de Miguel Fernández. son una muestra más de "la orientación esencial y esquemática de su poesía: barroquismo, tonalidad religiosa $y$ preocupación formal". Francisco Rincón, La poesía de Miguel Fernández, Valencia, Bello, 1978, pp. 117-119. Véase el artículo de Enrique Molina Campos; "Hacia una interpretación global de la poesía de Miguel Fernández", Hora de poesía, 8 (1980), pp. 78-85; y el capítulo dedicado a Sagrada materia en el libro de Sultana Wahnón ya citado.

4. Se trata de un lienzo de $79,5 \times 64 \mathrm{~cm}$. Las otras dos versiones son: un lienzo de $92 \times 73 \mathrm{~cm}$, de la Colección de Paul Mellon, de Washington, que representa al muchacho de pie: $y$ un dibujo y acuarela, de la Colección Feilchenfeld, de Zúrich, en la que el muchacho es retratado de frente y está sentado. Véase Frank Elgar, Cézanne, Barcelona, Daimon, 1969.

5. Karl Bühler, Teoría del lenguaje, Madrid, Alianza Editorial, 1979, pp. 143.

6. Véase S. Wahnón, ob. cit., p. 8?.

7. Ibídem, p. 118, nota 11 .

8. E. Molina Campos, art. cit.

9. S. Wahnón, ob. cit., p. 68.

10. Ibídem, pp. 83-84, nota 13.

11. Ibídem, p. 69.

12. Publicado con el título "Relato audiovisual y relato literario: para una narratología comparada ${ }^{n}$, en Investigaciones Semióticas $I V$, Madrid, Visor, 1992, Vol. I, pp. 299-307. 